\title{
Analysis of coordinated control of Beijing-Tianjin-Hebei smog based on evolutionary game theory
}

\author{
Yuan Qing-min ${ }^{1}$, Tan $\mathrm{Xin}^{2}$ \\ ${ }^{1}$ Tianjin University of Technology, Tianjin, China \\ ${ }^{2}$ Tianjin University of Technology, Tianjin, China
}

\begin{abstract}
Based on the perspective of ecological compensation and ecological claims, this paper analyzes the stability of Beijing Tianjin Hebei haze governance alliance by using asymmetric evolutionary game model, and obtains the optimal strategy combination. The results show that: a reasonable ecological compensation standard is very important for enterprises to adopt energy-saving and emission reduction strategies. Only when the total value of ecological claims in the two places is higher than the cost of energy-saving and emission reduction, enterprises will adopt energy-saving and emission reduction strategies, and the implementation of energy-saving and emission reduction strategies will not be shaken by the amount of ecological compensation.
\end{abstract}

\section{Introduction}

The haze problem in Beijing, Tianjin and Hebei and its surrounding areas is becoming increasingly serious. The key of haze governance lies in the environmental governance of Beijing, Tianjin and Hebei, and the key of environmental governance lies in whether the energy conservation and emission reduction work of relevant enterprises in Tianjin and Hebei is in place.

The literature about haze collaborative governance mainly focuses on policy, law and game theory. Based on the perspective of political science, Wang Huiqin and Zhu Deqing $^{[1-2]}$ pointed out that in the process of haze collaborative governance, we need to coordinate the relationship among the government, enterprises, the public, colleges and universities, and build a regional coordination mechanism. Based on the legal perspective, Liang pinghan ${ }^{[3]}$ found that the worse the legal environment, the more serious the regional illegal emissions. Wu Xiaoqian ${ }^{[4]}$ believes that it is necessary to improve the laws and regulations for the coordinated control of haze pollution. Based on the game theory, Xue $\mathrm{Jian}^{[5]}$ gives the cost sharing of air pollution control among Beijing, Tianjin and Hebei, and Bai Liyuan ${ }^{[6]}$ designs the game model of central, local and enterprises to analyze the haze control.

Based on the perspective of ecological compensation and ecological claims, this paper takes Beijing Tianjin Hebei haze governance as the research object, analyzes the stability of Beijing Tianjin Hebei haze governance alliance by using asymmetric evolutionary game model, and obtains the optimal strategy combination.

\section{Evolutionary Game Model and Stable Strategy}

\subsection{Asymmetric evolutionary game model}

For the collaborative governance alliance of Beijing Tianjin Hebei, the players mainly involve the Beijing government and the enterprises in Tianjin Hebei. The Beijing government can introduce more policy tools to influence the enterprises in Hebei and Tianjin. The strategies selected in this paper are the intervention policy based on the principle of "ecological compensation and ecological claim" and the laissez faire policy based on "who pollutes, who governs". The model shown in Table 1 gives the profit matrix of Beijing government, Hebei and Tianjin enterprises in their respective strategic behavior. $\mathrm{R}$ is the original income of the enterprises in the two places before they do not implement the policy, C is the cost of implementing the policy, $\mathrm{S}$ is the loss of the Beijing government when the enterprises in the two places do not implement the policy, $\mathrm{P}$ is the ecological compensation of the Beijing government to the enterprises in Tianjin and Hebei under the intervention policy, $A_{1}$ is the ecological claim of the local government when the enterprises in the two places do not implement the policy, $A_{2}$ is the ecological compensation of the Beijing government when the enterprises in the two places do not implement the policy Claim, the above parameters are greater than 0 .

\footnotetext{
*Corresponding author: 1138973432@qq.com
} 
Table 1. Asymmetric evolutionary game model of haze control alliance

\begin{tabular}{|c|c|c|c|}
\hline & \multicolumn{2}{|c|}{ Beijing government } \\
\hline & & Intervention policy & $\begin{array}{c}\text { Laissez faire } \\
\text { policy }\end{array}$ \\
\hline \multirow{2}{*}{$\begin{array}{c}\text { Enterprises } \\
\text { in Tianjin } \\
\text { and Hebei }\end{array}$} & execute & $(\mathrm{R}+\mathrm{P}-\mathrm{C}, \quad-\mathrm{P})$ & $(\mathrm{R}-\mathrm{C}, 0)$ \\
\hline & $\begin{array}{c}\text { No } \\
\text { execution }\end{array}$ & $\begin{array}{cc}\left(\mathrm{R}+\mathrm{P}-\mathrm{A}_{1}-\mathrm{A}_{2},\right. & \mathrm{A}_{2}-\mathrm{S}- \\
\mathrm{P}) & \end{array}$ & $\left(\mathrm{R}-\mathrm{A}_{1}, \quad-\mathrm{S}\right)$ \\
\hline
\end{tabular}

\subsection{Evolutionary stability strategy}

The laissez faire policy assumes that $\mathrm{x}$ is the proportion of enterprises that implement Beijing government's ecological compensation and ecological claim policies, then $1-\mathrm{x}$ is the proportion of enterprises that do not implement the policies; Suppose y is the proportion of Beijing government's intervention policy, then $1-y$ is the proportion of Beijing government's laissez faire policy.

Therefore, it can be concluded that the expected earnings $E_{11}$ and $E_{12}$ of enterprises in Hebei and Tianjin under two different strategies and the average earnings $\overline{E_{1}}$ of enterprises as a whole.

$$
\begin{gathered}
E_{11}=y(R+P-C)+(1-y)(B-C)=y P+R-C \\
E_{12}=\mathrm{y}\left(R+P-A_{1}-A_{2}\right)+(1-\mathrm{y})\left(R-A_{1}\right)=y P-y A_{2}+R-A_{1} \\
\overline{E_{1}}=x E_{11}+(1-x) E_{12}=x y A_{2}+x\left(A_{1}-C\right)+y\left(P-A_{2}\right)+R-A_{1}
\end{gathered}
$$

The expected revenue $E_{21}$ and $E_{22}$ of Beijing government under the two different strategies, and the average revenue $\overline{E_{2}}$ of the government as a whole are:

$$
\begin{gathered}
E_{21}=x(-P)+(1-x)\left(A_{2}-S-P\right)=x S-P-S+A_{2}-x A_{2} \\
E_{22}=x * 0+(1-x)(-S)=x S-S \\
\overline{E_{2}}=y E_{21}+(1-y) E_{22}=x S-y P-S+y A_{2}-x y A_{2}
\end{gathered}
$$

Through equations (1) (3) and (4) (6), we can get the multi population replication dynamic equation of haze control policy implementation and strategy choice of Beijing government.

$$
\begin{gathered}
\frac{d x}{d t}=x\left(E_{11}-\overline{E_{1}}\right)=x(1-x)\left(y A_{2}+A_{1}-C\right) \\
\frac{d y}{d t}=y\left(E_{21}-\overline{E_{2}}\right)=y(1-y)\left(x A_{2}+P-A_{2}\right)
\end{gathered}
$$

\subsection{Evolution path and stability analysis}

(1) Analysis on the evolution and stability of enterprise strategy

The differential equation obtained from equation (7) when enterprises implement Beijing government policies, Let $U(x)=\frac{d x}{d t}$, then:

$$
U^{\prime}(x)=(1-2 x)\left(y A_{2}+A_{1}-C\right)
$$

Let $U(x)=0$, then we got 12 suspected stable points $x_{1}^{*}=0, x_{2}^{*}=1$, Let $U^{\prime}(x)=0$, then:

$$
U^{\prime}(x)=(1-2 x)\left(y A_{2}+A_{1}-C\right)=0
$$

When $y=y^{*}=\frac{C-A_{1}}{A_{2}}\left(A_{1}<C \leq A_{1}+A_{2} 0 \leq y^{*} \leq 1\right)$, That is to say, when the enterprises implement the Beijing government's policies, the cost is greater than the punishment of the two governments when they do not implement the Beijing government's policy, and less than the sum of the claims of the two governments and the Beijing government when they do not implement the policy. At this time, $U^{\prime}(x) \equiv 0$, which means that when Beijing government chooses the intervention policy with the ratio of $\frac{C-A_{1}}{A_{2}}$, the system will always be in a stable state for any proportion of $\mathrm{x}$, and will not continue to evolve.

When $y>y^{*}=\frac{C-A_{1}}{A_{2}}, x_{1}{ }^{*}=0, x_{2}{ }^{*}=1$, are two suspected stable points. It can be concluded that $U^{\prime}(0)>0, U^{\prime}(1)<0$, According to the stability criteria of differential equations and the properties of evolutionary stability strategy, we can conclude that $x=x^{*}=1$ is an evolutionary stability strategy. It indicates that when the Beijing government chooses to intervene in the emission control of enterprises in the two places with a ratio higher than $\frac{C-A_{1}}{A_{2}}$, the enterprises in the two places will gradually evolve from non implementation of policies to implementation, that is to say, implementation of policies is the stable strategy of evolution.

When $y<y^{*}=\frac{C-A_{1}}{A_{2}}$ 时, $x_{1}{ }^{*}=0, x_{2}{ }^{*}=1$, are also two suspected points, Because $U^{\prime}(0)<0, U^{\prime}(1)>0$, So $x=x_{1}{ }^{*}=0=2$ is an evolutionary stable strategy. It indicates that when the Beijing government chooses to intervene at a ratio of less than $\frac{C-A_{1}}{A_{2}}$, the enterprises in the two places will gradually evolve from implementing environmental protection policies to not implementing them. At this time, non implementation is an evolutionary stable strategy.

(2) The evolution path and stability of Beijing government

Formula (8) gives the differential equation of Beijing government's intervention policy, Let $V(y)=\frac{d y}{d t}$, $V^{\prime}(y)=(1-2 y)\left(x A_{2}+P-A_{2}\right)$

Let $V(y)=0, y_{1}{ }^{*}=0, y_{2}{ }^{*}=1$, suspected points were obtained.

$$
V^{\prime}(y)=(1-2 y)\left(x A_{2}+P-A_{2}\right)=0
$$

When $x=x^{*}=\frac{A_{2}-p}{A_{2}} \quad\left(0 \leq x^{*} \leq 1, \quad P<A_{2}\right) \quad$ That is to say, the ecological compensation of Beijing government will not be greater than the ecological claim. At this time $V^{\prime}(x) \equiv 0$,It means that when the enterprises in Hebei and Tianjin choose to implement the Beijing government's policy with a ratio of $\frac{A_{2}-P}{A_{2}}$, the system is always in a stable state for any ratio of $\mathrm{Y}$, and will not continue to evolve.

2) When $x>x^{*}=\frac{A_{2}-p}{A_{2}}, V^{\prime}(0)>0, V^{\prime}(1)<0$ is available. According to the stability criteria of differential equations 
and the properties of evolutionary stability strategy, we can conclude that $y=y_{2}{ }^{*}=1$ is evolutionary stability strategy. It means that when enterprises in Hebei and Tianjin choose to implement the policies of Beijing government with a ratio of more than $\frac{A_{2}-P}{A_{2}}$, Beijing gradually evolves from laissez faire to intervention, that is to say, intervention policy is the stable strategy of evolution.

3 ) When $x<x^{*}=\frac{A_{2}-p}{A_{2}}, V^{\prime}(0)<0, V^{\prime}(1)>0$, is available. According to the stability criteria of differential equations and the properties of evolutionary stability strategy, we can conclude that $y=y_{1}^{*}=0$ is evolutionary stability strategy. It means that when enterprises in Hebei

and Tianjin choose to implement the policies of Beijing government at a ratio of less than $\frac{A_{2}-P}{A_{2}}$, Beijing gradually evolves from intervention to laissez faire, that is, laissez faire pre policy is the stable strategy of evolution.

\section{Parameter analysis of game theory evolutionary model between enterprises and governments in two places}

\subsection{Type judgment and stability analysis of equilibrium point of system}

In this paper, the local stability of Jacobi matrix is used to obtain the stability of equilibrium point.

Table 2. Judgment of equilibrium point type

\begin{tabular}{|c|c|c|c|c|c|c|c|c|}
\hline \multirow{2}{*}{$\begin{array}{l}\text { Coordinates of local } \\
\text { equilibrium point }\end{array}$} & \multicolumn{2}{|c|}{$\begin{array}{c}\mathrm{A}_{1}+\mathrm{A}_{2}>\mathrm{C} \\
\mathrm{A}_{2}>\mathrm{P} \\
\mathrm{C}>\mathrm{A}_{1}\end{array}$} & \multicolumn{2}{|c|}{$\begin{array}{c}\mathrm{A}_{1}+\mathrm{A}_{2}<\mathrm{C} \\
\mathrm{A}_{2}>\mathrm{P} \\
\mathrm{C}>\mathrm{A}_{1}\end{array}$} & \multicolumn{2}{|c|}{$\begin{array}{c}\mathrm{A}_{1}+\mathrm{A}_{2}>\mathrm{C} \\
\mathrm{A}_{2}<\mathrm{P} \\
\mathrm{C}>\mathrm{A}_{1}\end{array}$} & \multicolumn{2}{|c|}{$\begin{array}{c}\mathrm{A}_{1}+\mathrm{A}_{2}<\mathrm{C} \\
\mathrm{A}_{2}<\mathrm{P} \\
\mathrm{C}>\mathrm{A}_{1}\end{array}$} \\
\hline & $\mathrm{p} \mathrm{q} \Delta$ & result & $\mathrm{p} \mathrm{q} \Delta$ & result & $\mathrm{p} \mathrm{q} \Delta$ & result & $\mathrm{p} \mathrm{q} \Delta$ & result \\
\hline$(0,0)$ & -++ & Stable node & -++ & Stable node & $1-+$ & Saddle point & $1-+$ & Saddle point \\
\hline$(0,1)$ & +++ & Unstable node & $1-+$ & Saddle point & $1-+$ & Saddle point & -++ & Stable node \\
\hline$(1,0)$ & +++ & Unstable node & +++ & Unstable node & +++ & Unstable node & +++ & Unstable node \\
\hline$(1,1)$ & -++ & Stable node & --+ & Saddle point & -++ & Stable node & --+ & Saddle point \\
\hline $\begin{array}{l}\left(\mathrm{A}_{2}-\mathrm{P} / \mathrm{A}_{2}, \mathrm{C}-\right. \\
\left.\mathrm{A}_{1} / \mathrm{A}_{2}\right)\end{array}$ & $0+-$ & & & & Core & & & \\
\hline
\end{tabular}

$$
J=\left(\begin{array}{cc}
(1-2 x)\left(y A_{2}+A_{1}-C\right) & x(1-x) A_{2} \\
y(1-y) A_{2} & (1-2 y)\left(x A_{2}+P-A_{2}\right)
\end{array}\right)
$$

Trace of matrix:

$$
p=\operatorname{tr}(J)=J_{11}+J_{12}
$$$$
=-4 x y A_{2}+3 y A_{2}+2 x C-2 y P-2 x A_{1}+x A_{2}+A_{1}+P-C-A_{2}
$$

The value of the determinant of a matrix: $q=\operatorname{det}(J) J_{11} J_{22}-J_{12} J_{21}$

$=(1-2 x)(1-2 y)\left(y A_{2}+A_{1}-C\right)\left(x A_{2}+P-A_{2}\right)-x y A_{2}^{2}(1-x)(1-y)$

Delta value of matrix: $\Delta=p^{2}-4 q$

According to the stability discriminant formula of equilibrium point and the value of $\mathrm{qp} \Delta$, the stability of five equilibrium points $(0,0),(0,1),(1,0),(1,1), \quad\left(\mathrm{A}_{2}-\mathrm{P} / \mathrm{A}_{2}\right.$, $\left.\mathrm{C}-\mathrm{A}_{1} / \mathrm{A}_{2}\right)$ involved in the evolution system can be determined.

\subsection{Model parameter analysis}

Through the analysis of Jacobi matrix, it can be concluded that there are four cases of income among Beijing government, Tianjin and Hebei enterprises. In these four cases, four conclusions can be drawn.

Conclusion 1 in the absence of external supervision, because the cost of implementing the policy is higher than the local government's ecological claims, enterprises will not take the initiative to implement the policy.

Conclusion 2 when the ecological compensation is higher than the ecological compensation, it can not mobilize the enthusiasm of enterprises to implement the policy. Reasonable ecological compensation standard plays an important role for enterprises to adopt the strategy of energy conservation and emission reduction.

Conclusion 3 when the cost of policy implementation is higher than the sum of local government's ecological claim and Beijing government's ecological claim, enterprises will not choose to implement haze control policy. Too high ecological compensation makes enterprises prefer to accept claims rather than control pollution.

Conclusion 4 when the total value of ecological claims of local governments in Tianjin and Hebei and that of Beijing government is higher than the cost of implementing policies, it has a certain binding force on enterprises, and this binding force will not be affected by ecological compensation.

\section{Conclusion}

For the polluting enterprises in Tianjin and Hebei, the principle of profit-making and the principle of profit maximization is given to the enterprises, and the enterprises will not pay attention to the environmental problems in the adjacent areas. Therefore, in the absence of external control, enterprises will not take the initiative to implement energy conservation and emission reduction; for Beijing government, when the standard of ecological compensation is lower than its ecological claims for enterprises in Hebei and Tianjin, enterprises will not use their own funds to implement haze control policies; when the total value of ecological claims of the three governments is lower than the cost of implementing policies, it is difficult for enterprises to make progress The implementation of haze control policy, when Beijing's 
ecological compensation for enterprises is too high, enterprises will take the amount of compensation and pay the amount of claims instead of substantive pollution control; only when the total value of ecological claims of the three governments is higher than the cost of implementing the policy, it can have a certain binding force on enterprises.

\section{References}

1. Wang Huiqin, He Yiping. Haze governance mechanism from the perspective of synergy theory and its construction [J]. Journal of North China Electric Power University (Social Science Edition), 4 (2014): 24-27.

2. Zhu Deqing. Research on cross regional collaborative governance of environmental pollution [D]. Shanghai Jiaotong University, (2014)

3. Liang pinghan, Gao Nan. Personnel change, legal environment and local environmental pollution [J]. Management World, 23 (2014): 65-76

4. Wu Xiaoqian. Analysis on the dilemma and Countermeasures of collaborative governance of haze pollution in China [J]. Modern Communication, 4 (2015): 95-96

5. Xue Jian, Xie Wanlin, Li Changmin. Game model of inter provincial cooperation in air pollution control in Beijing Tianjin Hebei[J]. Theory and Practice of Systems Engineering, ,34 (2014): 810-816

6. Bai Liyuan, Fang Hua. Game Analysis of haze control [J]. Reform and Opening Up, 4 (2015): 71-74 